\title{
Key Engineering Highlights of Facilities \& Equipment for Oil \& Gas Production in Kuwait Oil Company
}

\author{
Babar Mirza $^{1}$ and Fahad Al-Kharqawi ${ }^{2}$ \\ 1. Senior Engineer Projects, Jurassic Projects Management Team, Kuwait Oil Company, Ahmadi 61008, Kuwait \\ 2. Team Leader Jurassic Projects Management, KOC, Ahmadi 61008, Kuwait
}

Received: April 21, 2015 / Accepted: July 01, 2015 / Published: January 31, 2016.

\begin{abstract}
The paper provides an insight into key engineering aspects of Kuwait Oil Company's existing projects, facilities and equipment both current and from nearly 30 years of projects development. It deals with engineering features of mainly process and mechanical equipment, both static and rotating besides others, used for collection, separation, desalting, heat transfer, chemical treatment, storage, transmission, pipelines and similar facilities utilized for upstream oil and gas production, both sweet and sour. Engineering highlights include certain technological developments, metallurgical aspects, few best practices and lessons learnt as well. Seven (7) case studies are included towards the end that show case some of the engineering aspects of facility equipment, lessons learned from their engineering and conclusions drawn that, emphasize the need to focus on initial, preliminary engineering aspects of projects and could provide useful tips for oil and gas engineers and designers.
\end{abstract}

Key words: Key engineering aspects, oil \& gas projects, surface facilities, equipment, case studies.

\section{Introduction}

This paper recalls the technical aspects of majority, if not all, of KOC's (Kuwait Oil Company's) surface projects, facilities and equipment including those that exist in conventional oil \& gas GC's (gathering centers), gas BS's (booster stations), EWDP's (effluent water disposal plants), WIP's (water injection plants), EPF's (early production facilities), pilot injection plants, aquifer water centers and bulk chemicals storage facility.

\section{Upstream Sweet Oil \& Gas Production, Storage \& Transmission (GC's and BS's)}

Fig. 1 below depicts KOC's typical sweet oil production units of GC's of early Burgan, Magwa, Ahmadi and North Kuwait areas. The GC's comprise of conventional steel flow lines that link the well heads

Corresponding author: Babar Mirza, MS (Mech. Eng.), research fields: oil, gas \& power engineering, facilities layouts, selection \& design, FEED (front end engineering design) and detail design reviews. to the GC followed by the incomer dry and wet headers inside the GC, the HP (high pressure) \& LP (low pressure) separation units, de-salters, heaters, chemical treatment units, in-plant storage and pumping station at GCs that pump transit crude into the crude oil network. Crude oil is subsequently stored in the tankage areas of North and South tank farms at Ahmadi before being dispatched by gravity lines to respective north and south piers for exporting through marine tankers and/or is transmitted as feedstock to downstream KNPC (Kuwait National Petroleum Company) refineries. The separated rich gases, the compressed tank vapor gas and condensate at GC's are transported by HP, LP \& condensate pipelines to the designated BS (booster station) of the area, where gas is compressed and dehydrated gas \& condensate are transferred by pipelines to KNPC refineries.

The incomer flow lines to GCs are mostly 6" carbon steel API (American Petroleum Institute)-5L Gr. B pipes laid above ground and designed to ASME (American Society of Mechanical Engineers) B31.4. 


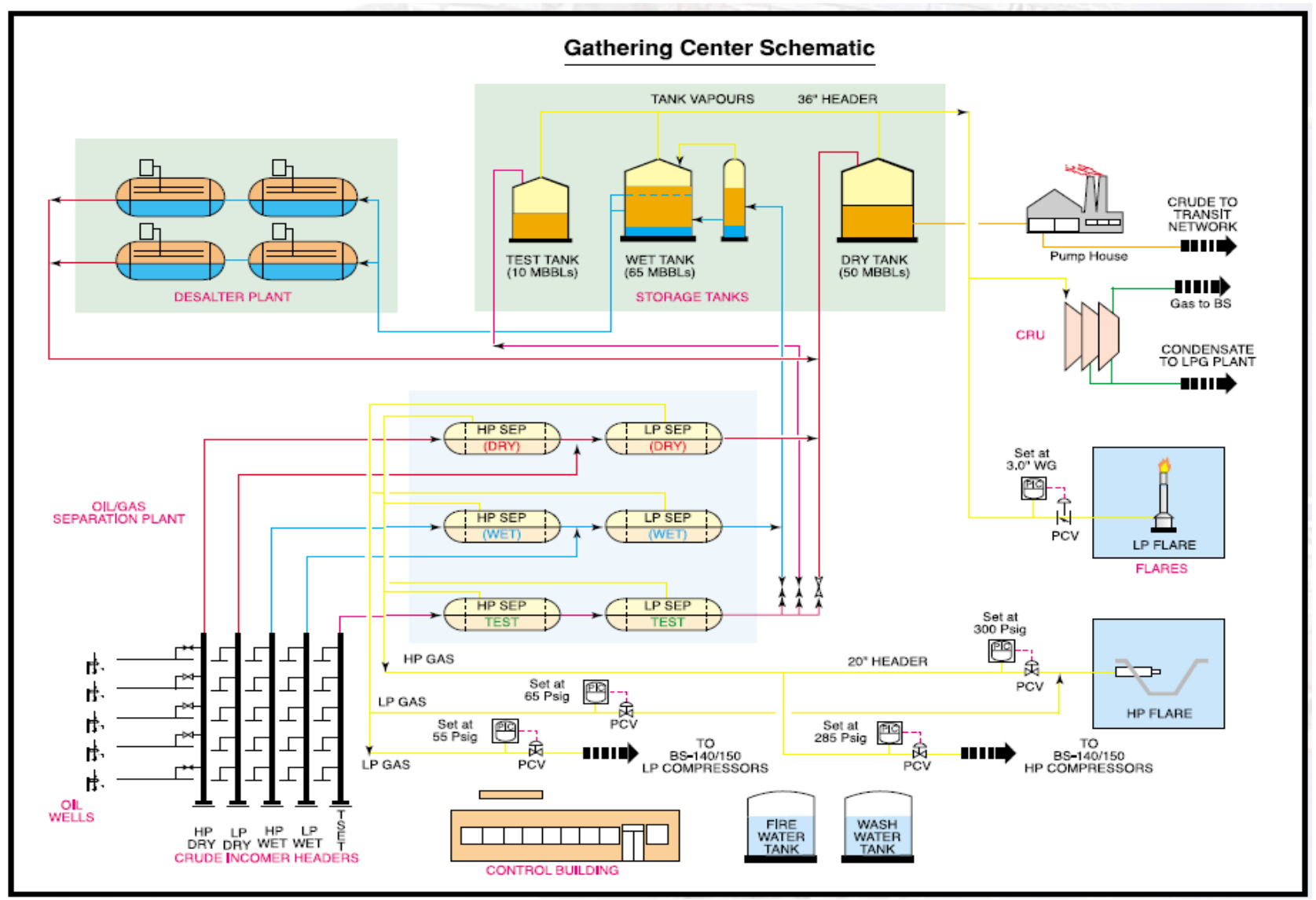

Fig. 1 Gathering center schematic.

The headers and incoming piping inside GCs are also of carbon steel material designed to ASME B 31.3 with flanges generally of class \#600 in SEK (South East Kuwait) areas, \#900 in WK (West Kuwait) and \#1500 in NK (North Kuwait) areas. However, some of the new flow lines are \#1500 in SEK \& \#600/1500 in WK.

Being first in the process flow path, the HP and LP separators were installed initially as 2-phase equipment while in some GCs, the 3-phase separators are installed but still operate in 2-phase mode. The separators are mostly horizontal pressure vessels having various designs normally to API 12J, ASME VIII and are generally equipped with inlet deflector, separation packs, anti-foam device, weir plate, demister pad, pressure and level controls, safety and blow down equipment and piping.

Further on, the de-salters are usually designed as two stage vessels (ASME VIII) of either single polarity
(DC) machines as initially installed or are dual polarity AC/DC machines installed later in GCs. Depending on the nature of crude and its composition and properties like specific gravity (API gravity), viscosity, temperature etc., the de-salter staging details, its internals, the internal electrical grids, chemical injection, mixer and wash water requirements are determined and when necessary external crude heaters are utilized, which are mostly indirect fired heaters packaged with the de-salter. In early KOC days, the de-salters were installed in four phases: Phase I (by BS \& B, USA), Phase II (Toyo, Japan), Phase III (Machino-import, Russia), Phase IV (Technip/Tecnologie Progetti Lavori, Italy).

The chemicals injected are de-mulsifiers, CI (corrosion inhibitors), SI (scale inhibitors) or combined $\mathrm{CI} / \mathrm{SI}$, oxygen scavengers and biocides, which are executed by means of packaged chemical injection skids. 
The crude storage tanks (wet, dry and dual) in GCs are all fixed conical roof type welded atmospheric tanks built to API-650.

The GC crude export pump units (transit pumps) typically comprised of a vertical motor driven booster pump feeding into a gas turbine driven horizontal split case main transit pump. Afire wall separated the gas turbine from the pump area. At some GC's, the transit pumps were fixed speed motor driven.

Moving on to the gas stream, the tank VRU (vapor recovery unit) compressor at GC's is a robust, sturdy but noisy 3 stage reciprocating CB (Cooper Bessemer) compressor driven by an integral top mounted gas engine with packaged units \& systems, which is presently being utilized as standby unit after its replacement with centrifugal compressor. The associated HP \& LP gases are directly routed to the designated area BS. TV gas is sent through HP network, however at GC's 7, 8 \& 21, the new TV centrifugal gas compressor transports gas via LP network to BS-150.

The crude storage tanks at STF (South tank farm) and NTF (North tank farm) located at Ahmadi are floating roof type tanks built over a period from 1950s to 80 s. In early 90 s, these tanks were equipped with proper fire-fighting systems that comprised of perhaps one of the world's largest pumped foam protection, proportioning and piping network system for an oil storage tank farm together with large diesel engine driven fire-water pumping and protection systems built in accordance with relevant NFPA (National Fire Protection Association) standards.

In addition to this, the fire-fighting systems at all GC's were revamped with provision of a fire-water tank, main fire pumps and jockey pumps located outside and a fire fighting system inside the GC's.

Fig. 2 indicates typical gas booster stations that comprise mainly of gas turbine driven centrifugal gas compressors (API-617) and gas de-hydration units with all associated utilities and safety provisions. Brief configuration of all booster stations is summarized in Table 1 below.
Interestingly, gas turbines used for power generation and crude pump/gas compressor drives in KOC during 1957 to 1987 were 79 nos. in total from eight (8) world-reputed gas turbine manufacturers and had overall power rating above 550,000 HP (410 MW), the largest being 33,550 HP (25 MW) GE (General Electric) frame 5 unit [1]. Both the industrial types as well as aero-derivative type gas turbines were in use.

\section{FMP (Facilities Modernization Project)}

With the advent of increased water cuts in reservoir fluids and to cater for higher production demands, KOC embarked upon major facility upgrades and revamping initiatives. New 3-phase separators were installed, some 2-phase oil-gas separators were converted to 3-phase separators having water boots and some are in conversion phase while most of the separators continue to operate in 2-phase mode. Several oil-water treatment systems were tried and installed, in addition to intake headers extensions and addition of several new trains and equipment. Amongst the oil-water separator systems, tried and tested in KOC were the traditional gravity separators and flotators like CPI (corrugated plate interceptors), API (Assorted), DAF (dissolved air flotators) \& IGF (induced gas flotation) units. Hydro-cyclones and TORR (total oil removal \& remediation) equipment are also installed. The technology presently adopted as reliable and proven for produced oil-water separation appears to be controlled gravity separation in volume tanks wherein adequate residence time is provided for oil-water separation that is further enhanced by chemical injection and filtration techniques. Oil is skimmed at the top of tank.

The water handling capacity of separators, de-salters and associated equipment were reviewed and more appropriate custom-built equipment were provided. Wet crude tanks and dual purpose (wet and dry) tanks were added, effluent storage tanks and surge tanks were built and effluent pumps were installed. Many chemical Injection facilities were installed and/or existing units were upgraded. 


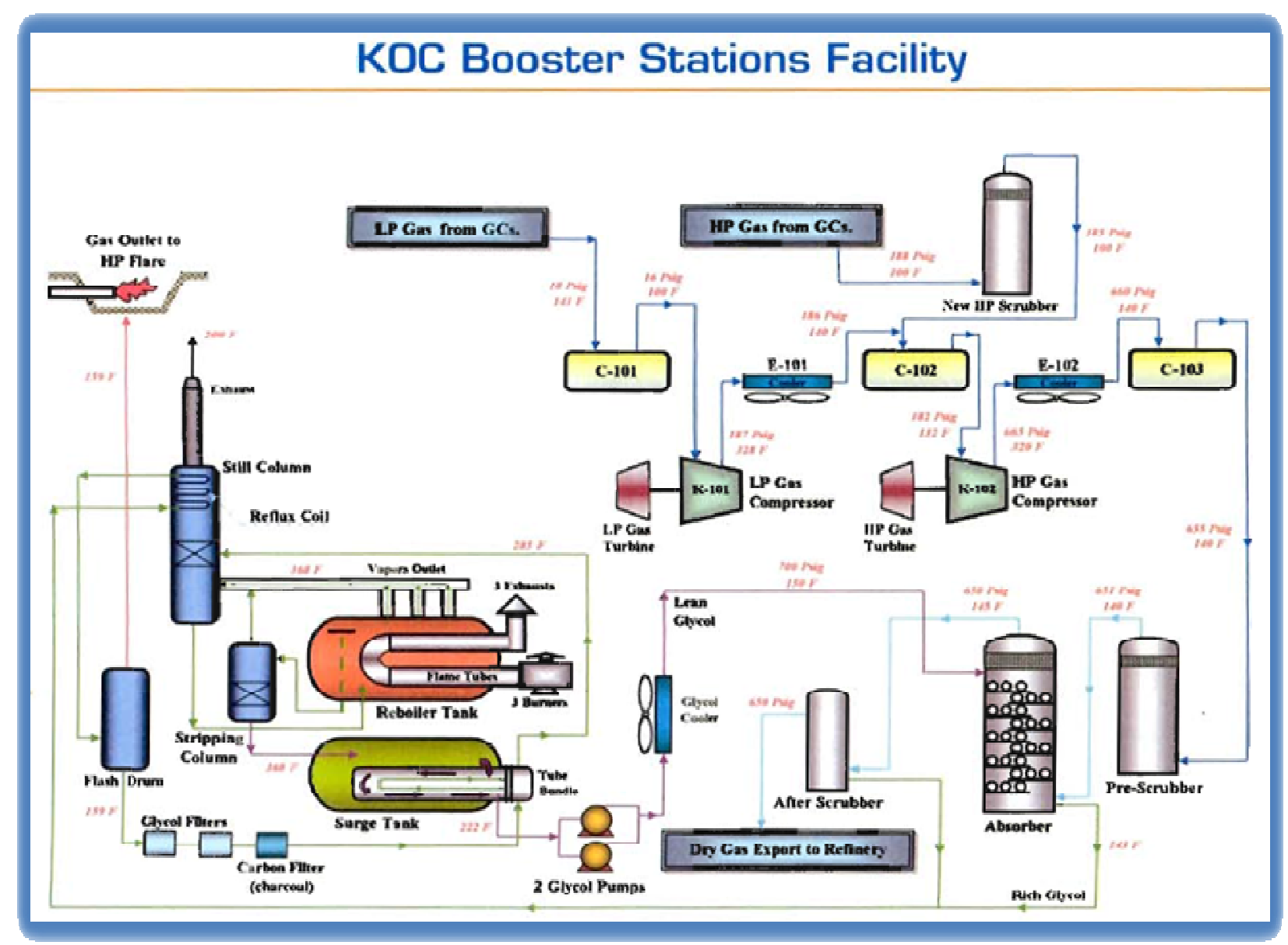

Fig. 2 KOC booster stations facility.

Table 1 Brief configuration at KOC's gas BS's: GT—gas turbine.

\begin{tabular}{lllllllllll}
\hline Asset area & \multicolumn{4}{c}{ South \& East Kuwait } & & \multicolumn{2}{c}{ West Kuwait } & & \multicolumn{2}{c}{ North Kuwait } \\
\hline Booster station & 140 & 150 & 160 & 180 & & 170 & 171 & & 131 & 132 \\
Gas handled & Rich & Rich & Rich & Fuel gas & Sour gas & Sour gas & Rich & Rich \\
No. of compression trains & 2 & 3 & 2 & $3+1$ & & 3 & $2+1$ & 2 & 1 \\
Compressor drive & GT & GT & GT & GT & GT & GT & GT & GT \\
\hline
\end{tabular}

Another notable feature with higher water cuts was the change in metallurgy of hydrocarbon handling equipment and piping from plain carbon steel or low alloyed carbon steel to exotic materials like use of stainless steels (e.g., 316/316L), CRAs (corrosion resistant alloys), duplex stainless steels, super duplex stainless steels and non-metallics like GRE (glass reinforced epoxy/GRP (polyester)/RTRP (reinforced thermoset resin plastic pipe) and RTP (reinforced thermoplastic pipe) for effluent water lines. Ferrous materials are invariably required to comply with standards like NACE (National Association of Corrosion Engineers) MR0175/ISO 15156 and associated NACE testing procedures.

The 1st EPF (early production facility) of KOC post 1990 was built at GC-17, WK, which has subsequently undergone major modifications, up-gradation and expansion of water handling facility as well.

Due to increased safety concerns and insurance requirements, the underground piping and piping systems in all associated GCs were required to be relocated aboveground resulting in major facility 
modernization projects for SEK, NK \& WK areas, whereby several GC equipment were also added and upgraded [2]. The rotating equipment like pumps and compressors involved in crude and gas export were equipped with VSM (variable speed motor) driven bespoke centrifugal pumps (API-610) and compressors (API-617), respectively. The previous, old rotating equipment are being used as standby units.

The heat transfer and heating equipment used in KOC are coolers, heaters, flares and more recently the boilers and waste heat recovery units. All types of heat exchangers like shell \& tube type of various API 660 configurations, air cooled heat exchangers as per API 661 and plate heat/frame type as per API 662 are in use. Crude heaters are indirect fired heaters and flares are mostly smoke-less, pilot operated, vertical, air-assisted flares, Coanda flares and burn pits etc. with ignition panels.

In view of stringent statutory HSE (health, safety and environmental) regulations that prohibit surface disposal, the effluent water that was being pumped to evaporation pits constructed nearby GCs/tank farms had to be injected into shallow disposal wells after further chemical and mechanical treatment.

As a consequence of enhanced water cuts and production demands, the crude storage tanks at STF \& NTF had to be equipped with new facility for handling increased bottom water levels, new drainage facility, new level measurement (tank gauging) techniques and custody transfer facilities were installed apart from installing new very large crude oil tanks.

Furthermore, as part of IOR (increased oil recovery) technique, ESPs (electro-submersible pumps)-PC type or SRP (sucker rod pump) are installed in some wells of SEK, WK \& NK areas and a stronger steel grade for flow line material, API-5L Gr. X52, started to be used. SSVs (surface safety valves) are now installed on all KOC flow lines with line flanges from wellhead to SSV generally to API-6A \# 2000 upstream/ASME \# 600 downstream or API-6A \# 5000 upstream/ASME \# $1500 \mathrm{~d} / \mathrm{s}$, depending on the wellhead pressure classes, choke provisions and related requirements.

Due to the gradual phased availability of MEW (Ministry of Electricity \& Water) grid power, high-energy consuming rotating equipment like new HP pumps at GC's/EWDP's and compressors at GC's were specified with variable speed electric motor drives instead of gas turbine/engine drives. Under the modernization projects, new CRU (condensate recovery unit) at SEK GC's are installed with VSD (variable speed drive) motors and new export pumps at GCs are also installed with VSD motors.

\section{Water Injection System and Water Facilities}

KOC has ventured into a well-planned and major water injection program for pressure maintenance of several of its mature and newer field reservoirs.

Starting with temporary pilot water injection plants built in mid 1980s for two wells of Minagish field, KOC has undertaken several (7-8) pilot water injection plants, other than those in KGOC (Kuwait Gulf Oil Co.), Wafra. These were 1 Rawdhatain injector (near GC-23), Wara pilot, SEK (2 injectors), Marrat pilot, Magwa (1 injector), Dharif, WK (1 injector) and another planned Jurassic pilot, NK (1 injector).

Minagish injection plant, WK was originally designed for dual water source i.e., brackish (aquifer) water from new source wells as well as effluent water from GC's 17, $27 \& 28$ and both waters had to be strictly segregated due to their non-compatibility and likely scale formation if commingled. The plant uses high pressure injection pumping system and was recently upgraded and new pumps were added.

CIPF (central sea water injection plant facility), NK utilizes treated sea water, pressurizes it using high-pressure injection pumping system and injects into North Kuwait field area injectors. Phase II of the project utilizes treated effluents from NK GCs to cater for the powered water flood program.

The two EWDP's, one in Maqwa (EWDP 1) and another in SEK (EWDP 2) together assimilate effluent 
water from all SEK GCs, treat them and inject sub-surface at high pressure into shallow disposal wells. The preliminary design of these plants was conducted in late 1980s. Media filters are used upstream of HP pumps to separate particulate matter and possibly oily content from the effluent stream. Chemicals like CI/SI, $\mathrm{O}_{2}$ scavenger and biocides are also injected at the EWDPs.

A major water injection project is underway for Wara pressure maintenance at SEK and a new pilot steam injection plant is in progress using steam flood technique for heavy oil pilot EOR (enhanced oil recovery) studies in NK.

Moving on to utility water, the main source of brackish water supply for SEK \& WK areas is Abduliyah pump station, WK, and water is distributed through the water handling section of STF. North Kuwait has its separate brackish water center at GC-190, which is undergoing major upgradation. Fresh water for SEK \& WK is sourced from Mina Al-Zoor treatment plant via water pipeline with pressure boosted at Supervisory pump house near KNPC area, followed by water storage tanks and brackish/fresh water pump station located at STF. Fresh water distribution pipeline in WK is of HDPE (high density poly-ethylene) material.

\section{Pipelines Network for Crude, Gas, Condensate, Water and Fuel Gas Handling}

A comprehensive and intricate network of pipelines exists for distribution and handling of crude oil, HP gas, LP gas, condensate, lean fuel gas, brackish/aquifer water, effluent water and fresh water to various consumers and destinations [3]. Hydrocarbon handling pipelines are mostly of carbon steel material (API 5L Gr. B/Gr. X52) and ranging in sizes up to 48 ", while some lines/headers are 52", 54", maximum 60" size. New effluent water pipelines in SEK and WK are in RTRP material up to 24" diameter, while HP effluent water injection/disposal lines are FBE (fusion bonded epoxy)/HDPE lined carbon steel or RTP material and fresh water distribution pipeline in WK is of HDPE material.

Importantly, the oil, condensate, liquid and water pipelines are designed in accordance with ASME B 31.4 and gas pipelines are designed as per ASME B 31.8.

MPSV (multi-port selector valves)/field manifolds are recently installed in SEK areas and are also considered for future projects in order to reduce the congestion and foot print area of flow line corridors in the field areas.

\section{Bulk Chemicals Handling Facility, Burgan}

With the increased consumption of chemicals throughout the asset areas of KOC and due to the nuance of ensuring their timely availability, storage of chemical drums, spacing requirements and the growing HSE concerns, a centralized bulk chemical storage and handling facility was conceived, conceptualized and is presently under advanced construction completion phase.

The centralized, primary facility located in Burgan comprises of chemical storage tanks and pumping facility for de-mulsifiers (two types), corrosion inhibitors, scale inhibitors, $\mathrm{O}_{2}$ scavenger, biocides, utilities. Further internal distribution of these chemicals to various GCs and EWDPs would be by road tankers.

Chemicals used at the end user GCs and EWDPs are handled by secondary facilities which include smaller chemical tanks, chemical injection pumps and piping system to the requisite injection points inside the consumer facilities.

Specifically, the tanks, pumps and piping handling most chemicals are in SS 316/316L material while for de-mulsifiers carbon steel is used.

\section{Sour Crude and Sour Gas Handling Facilities}

Due to the presence of considerable amount of $\mathrm{H}_{2} \mathrm{~S}$ in West Kuwait fields of Minagish, Umm Gudair and in the Jurassic fields of North and West Kuwait and also due to some SEK \& other fields recently turning 
sour, the reservoir fluids of these formations needed specialized equipment and materials for sour $\left(\mathrm{H}_{2} \mathrm{~S}\right)$ hydrocarbon handling.

For this reason, in West Kuwait area, sour crude and gas handling equipment, the piping and pipelines are constructed as per NACE compliance. Sour gas and crude are sent directly to KNPC for sweetening and treatment, whereas a new plant is built and another underway in WK for sour gas sweetening.

The sour reservoir fluids of deep drilled Jurassic wells, NK, are at fairly high wellhead pressures (about 1,100-1,400 psi) downstream of the chokes with well shut in pressure of around 10,000 psi and design temperature of $220^{\circ} \mathrm{F}$. This calls for high pressure rated valves and solid/clad Inconel 825/625 material pipes \& valve trim in the immediate vicinity of wellheads. The Jurassic wellheads are API class \# $15 \mathrm{~K}$ rated and the flow lines are ASME \# 1500 with transition spec breaks. The flow line material downstream of corrosion inhibitor (\& scale inhibitor) injection points is carbon steel to API-5L Gr. X52.

The sour hydrocarbon fluids need special crude and gas treatment facilities and equipment like crude stabilizer (steam/hot oil heated) for oil treatment, gas sweetening plants involving proprietary technologies, various types of solvents and gas sweetening media like Amine (MDEA (methyl diethanol amine)/DEA (diethanol amine) etc.) and specialized equipment likes our gas scrubbers (with special internal elements), contactor/absorber towers, coalescing type gas-oil filters, regenerators, re-boilers, compressor trim coolers, glycol (TEG (tri-ethylene glycol)) de-hydrators, special materials and other specialties depending on technology selection.

Amine handling equipment material is required to comply generally with API RP 945. SWS (sour water stripper) for produced water treatment may also require steam heating or fuel gas stripping. Figs. 3-5 depict three typical facilities and equipment installed for sour hydrocarbon handling at early production facility-EPF-50.

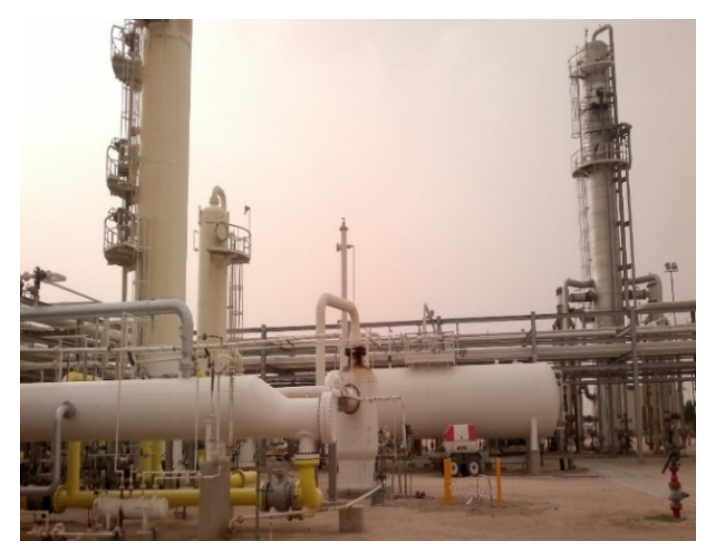

Fig. 3 Trim cooler \& amine columns.

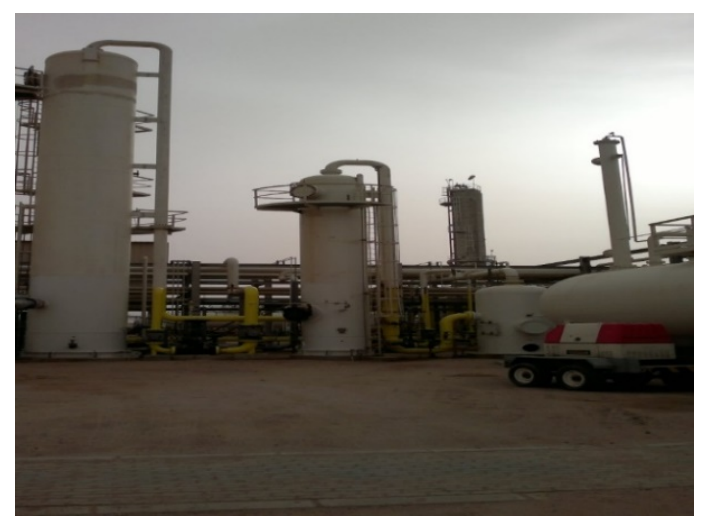

Fig. 4 Crude stabilizer \& glycol (TEG) columns.

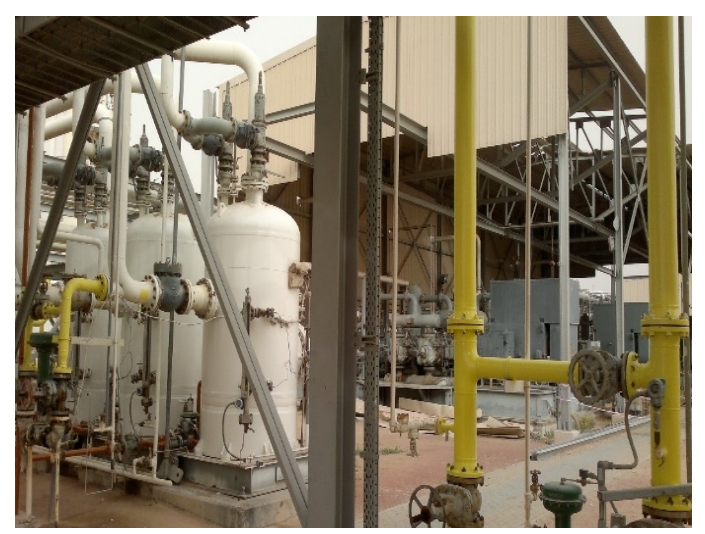

Fig. 5 Gas scrubbers \& compressor.

Sour crude and gas equipment, piping and piping components are required to comply with NACE MR0175/ISO 15156 and NACE TM0284 testing standard. The techno-commercial challenges meted out for the use of exotic CRAs (corrosion resistant alloys) like super duplex stainless steels, Monel, Inconel $825 / 625$, Hastelloy and similar materials are on-going with simultaneous updating of KOC standards and specifications for materials. 


\section{Case Studies}

To illustrate some of the engineering aspects of surface equipment used in the above-mentioned facilities, the following case studies and lessons learned from them with conclusion are noted below in brief.

\subsection{Case Study 1: Importance of Correctly Specifying} Centrifugal Pumps (Built to API-610)

Case brief: When specifying centrifugal pumps, it is common practice to specify certain design margins over pump capacity and head. These margins should be carefully selected in the initial stages so as not to over-specify the pumps, since this could result in requirement for discharge valve throttling, power wastage, operational concern, motor overload trip during pump start-ups, can adversely affect pump impeller/trim performance, increase wear-tear and reduce equipment life.

Technical concern: De-salter feed pump in a GC was tripping on motor overload during start-up.

Solution: On analysis, it was observed that, the pump head/pressure was over-specified resulting in excessive flow causing motor overload. Pump discharge valve throttling was introduced, as shown in Fig. 6, consequently pump flow \& power absorbed were reduced and the motor started smoothly.

Lesson learned: Care should be exercised when specifying pumps to avoid excessive overdesign, the extent of design margins would depend on case-by-case considerations.

\subsection{Case Study 2: Screw Compressor Type Selection} (API-619) for Handling Gases with Entrained Liquid Hydrocarbons

Case brief: During the compressor type selection for handling low suction pressure gases having liquid hydrocarbon carry-overs and other contaminants, as in the case of crude oil TV (tank vapor) gas compression, extreme care must be taken in beginning when specifying screw compressors to ensure that, these

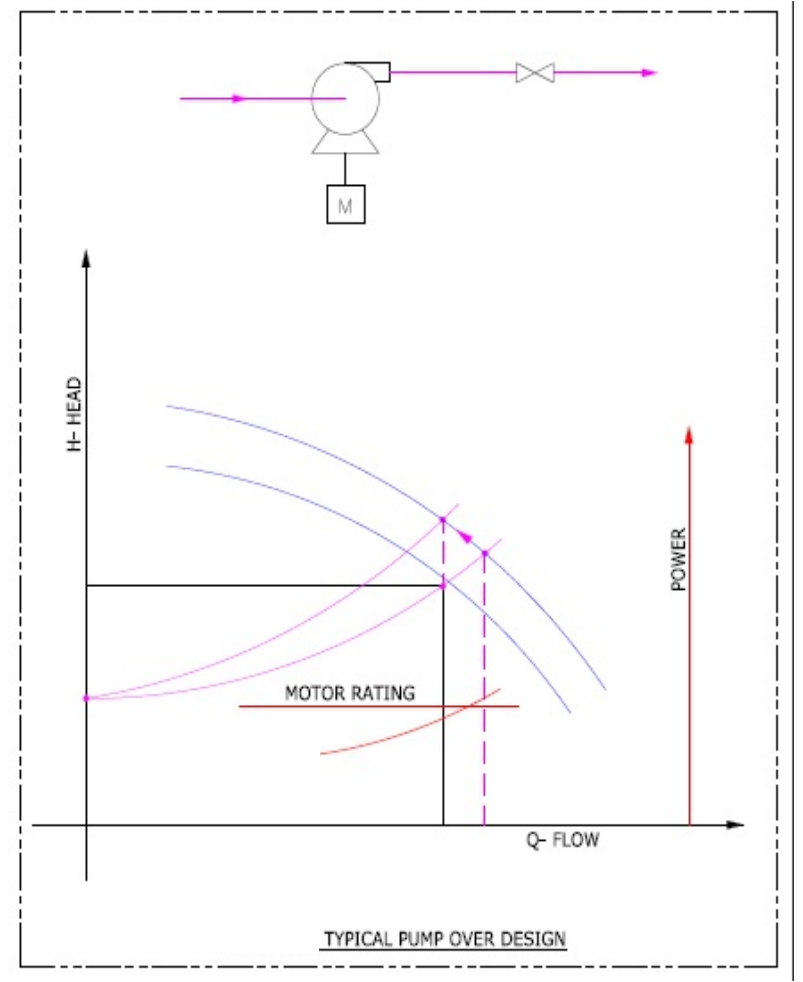

Fig. 6 Over-specified pump performance.

machines shall be of dry, non-lubricated, oil-free trim design. Screw compressor selection should avoid mixing of trim lubricant with entrained liquid contaminants resulting in formation of thick and viscous $\mathrm{HC}$ compounds under high temperatures and pressures, which seriously impairs the integrity and performance of compressors.

Technical concern: On start-up, the oil-flooded screw compressors were being jammed, plugged and the trim ceased to rotate within short time, resulting in start-up and integrity concerns.

Solution: New compressor type selected-The CRU at SEK GC's is now equipped with new high reliability centrifugal compressor (built to API-617), such a 2-stage compressor having both the stages mounted on a common shaft driven by single variable speed motor is shown in Figs. 7 (1st stage) and 8 (2nd stage) below.

Lesson learned: Specify either dry screw type or centrifugal compressor for wet TV gas compression.

Do not specify wet, lubricated (oil-flooded) screw compressors for handling gases with entrained liquid hydrocarbons. 


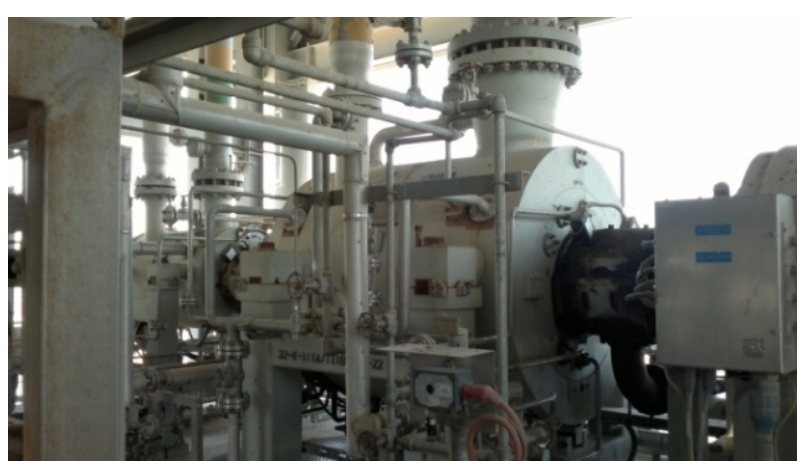

Fig. 7 New compressor 1st stage \& motor.

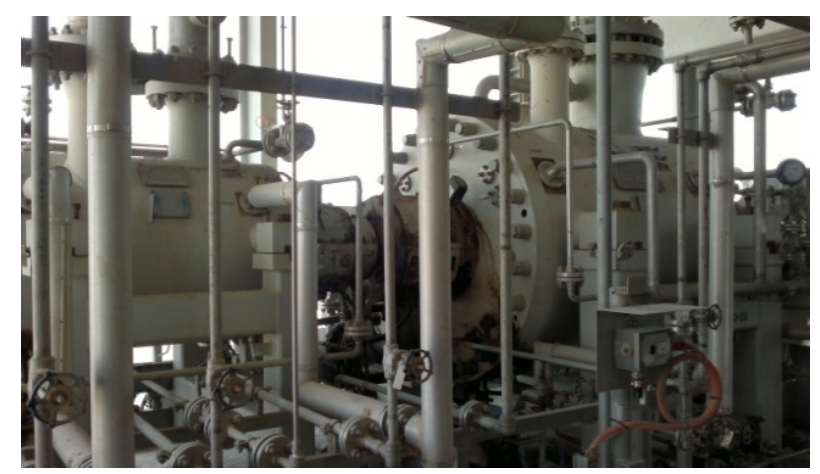

Fig. 8 New compressor 2nd stage.

\subsection{Case Study 3: Effluent Water Handling Tanks at} GCs (Internal Oil Skimmer Design)

Case brief: In effluent water tanks, the top oil layer/film is removed by an in-built skimming device.

Technical concern: The floating type oil skimmer arrangement originally specified proved to be unreliable, as the floats required regular monitoring and maintenance.

Solution: A new design stationary skimming system with weir box is developed to collect the oil. Fig. 9 illustrates such a typical fixed type skimmer inside an effluent water tank.

Lesson learned: Floating type oil skimmer is ineffective as a skimming devise.

\subsection{Case Study 4: Large Fire Water Pumps, Diesel Engines \& Foam Pumps at Oil Tank Farms}

Case brief: Some of the largest engine driven (1,500 HP) fire water pumps, built as per NFPA 20, exist at STF and NTF along with a very extensive foam pumping \& proportioning system (built per NFPA 11).

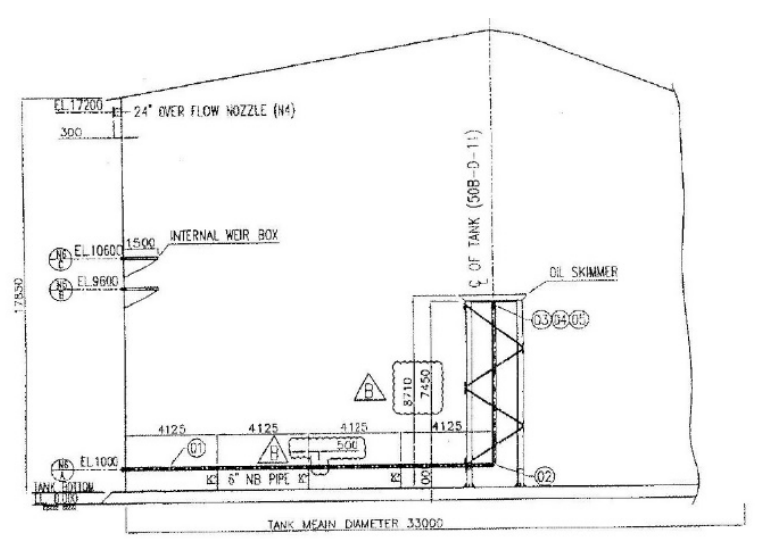

Fig. 9 Fixed oil skimmer in effluent tank.

Diesel engine cooling: In the large engines of firewater pumps, the primary \& secondary coolant is treated water in closed circuit with fan/air-cooled tertiary cooling, while old engines had water as tertiary coolant. Figs. 10 and 11 represent the old \& new fire water pumps \& engines, respectively.

Lesson learned: For large engines, specify tertiary air-cooling where water supply is scarce or when difficult to ensure supply of cooling water during start-up and shut down.

Foam system brief: Foam pumps with foam concentrate tank (Fig. 12) are at the heart of large foam protection system, the pumps are single screw, progressive cavity type rotary units handling viscous foam concentrate.

Lesson learned: Care must be taken during and after the system testing with foam concentrate, liquid foam proportioner and foam generator/pourer to drain the system in order to avoid clogging of piping, by providing proper pipe slopes and appropriate draining facility.

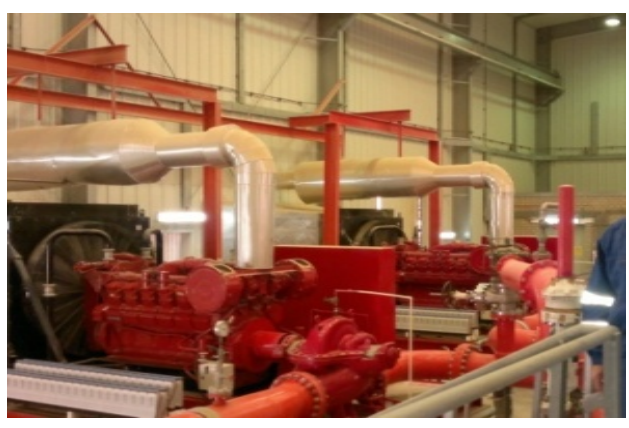

Fig. 10 Old FW (fire water) pump. 


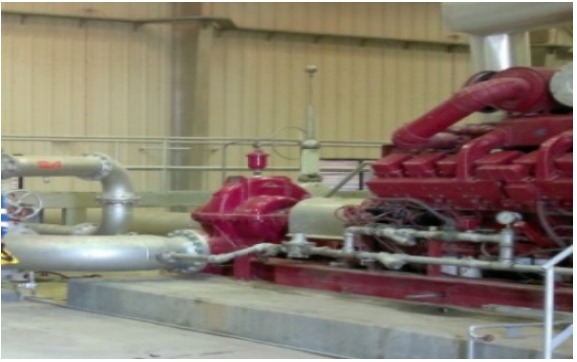

Fig. 11 New pump.

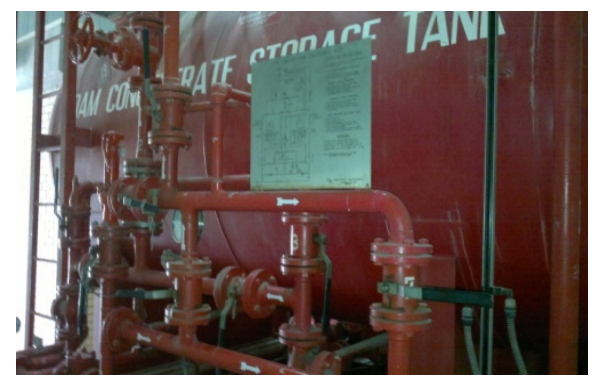

Fig. 12 Foam tank \& pumps skid.

\subsection{Case Study 5: Marrat Pilot Water Injection Plant (Internal Coating of HP Pipe Joints)}

Case brief: Due to the high-pressure requirements of asphaltene set-in at deep Marrat wells of Magwa area, very high-pressure injection pumps (7,200 psi), FBE lined piping and special valves class \# 4500 were required for Marrat pilot water injection plant. HP reciprocating pumps (plunger/piston type) with VSD motors were installed. The Marrat water tank, HP pump skids and piping are shown in Figs. 13-15, respectively.

Concern: Internal lining of HP pipe joints could not be accomplished.

Lesson learned for HP piping/pipeline joints coating: An alternate technology for internal lining of welded joints of short distance HP injection pipe needs to be developed, alternatively new technology must be adopted.

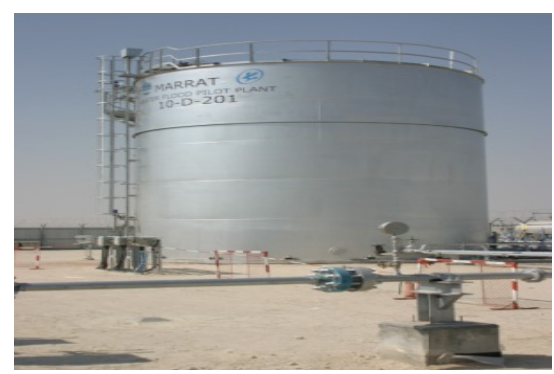

Fig. 13 Marrat water tank.

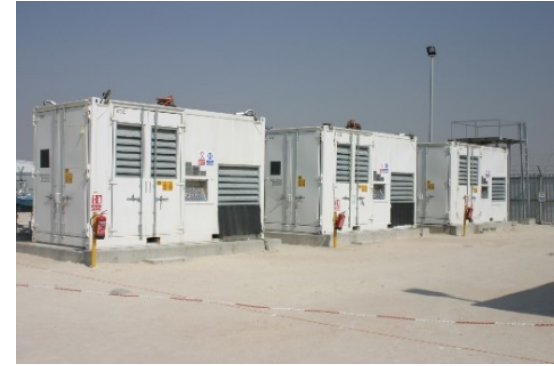

Fig. 14 Marrat HP pump skids.

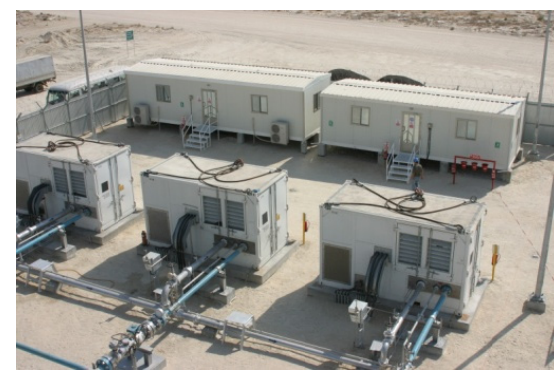

Fig. 15 Marrat HP injection piping.

8.6 Case Study 6: Bulk Chemicals Handling Facility, Burgan (System Logistics)

The primary, centralized bulk chemical storage plant and its scaled model are depicted in Figs. 16 and 17, while Figs. 18 and 19 (typical) show the chemical facilities at secondary consumers like GC's \& EWPD's.

Lesson learned for system logistics: For the successful implementation of entire bulk chemical handling facility system, the logistics of chemical transportation, road tanker movement system and the associated TAS (terminal automation system) need to be well integrated and coordinated right from the beginning of the project.

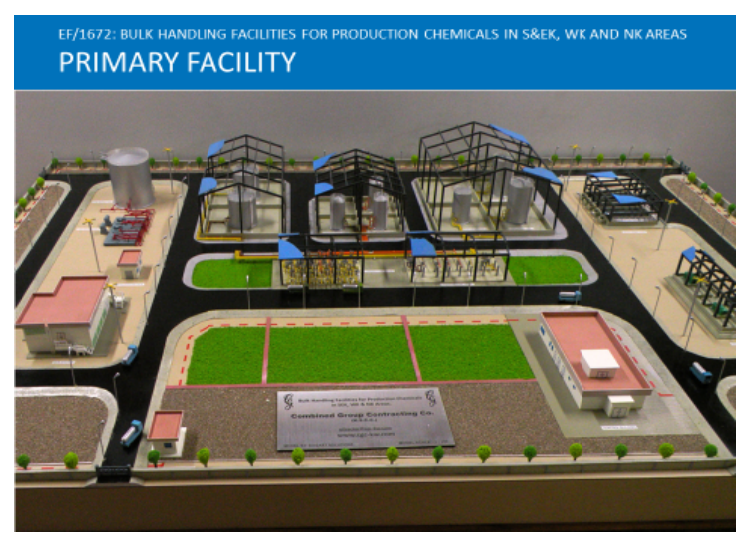

Fig. 16 Primary chemical plant model. 
EF/1672: BULK HANDUNG FACIUTIES FOR PRODUCTION CHEMICALS IN S\&EK, WK AND NK AREAS PRIMARY FACILITY

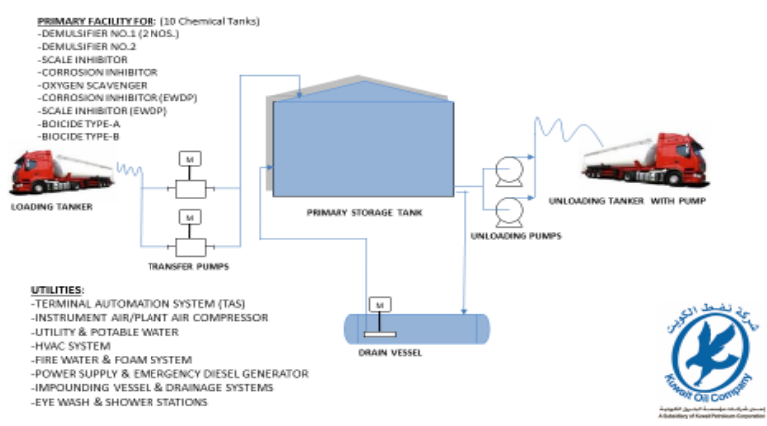

Fig. 17 Primary chemical plant schematic.

EF/1672: BULK HANDUNG FACIUTIES FOR PRODUCTION CHEMICALS IN S\&EK, WK AND NK AREAS SECONDARY FACILITIES

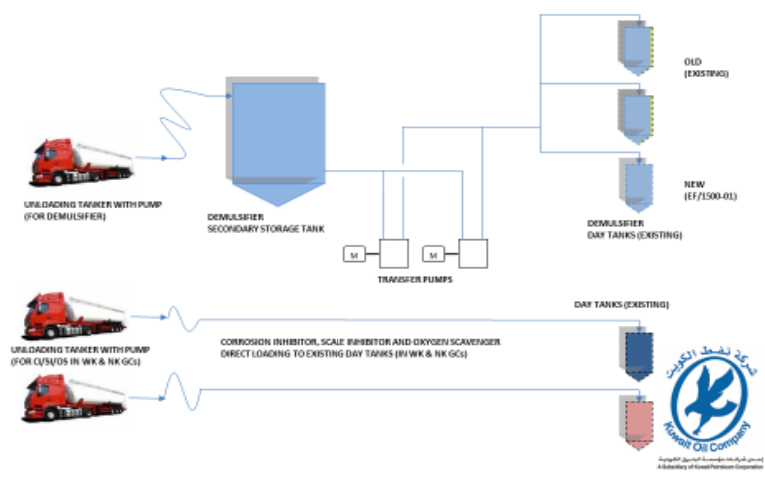

Fig. 18 Secondary chemical plant schematic.

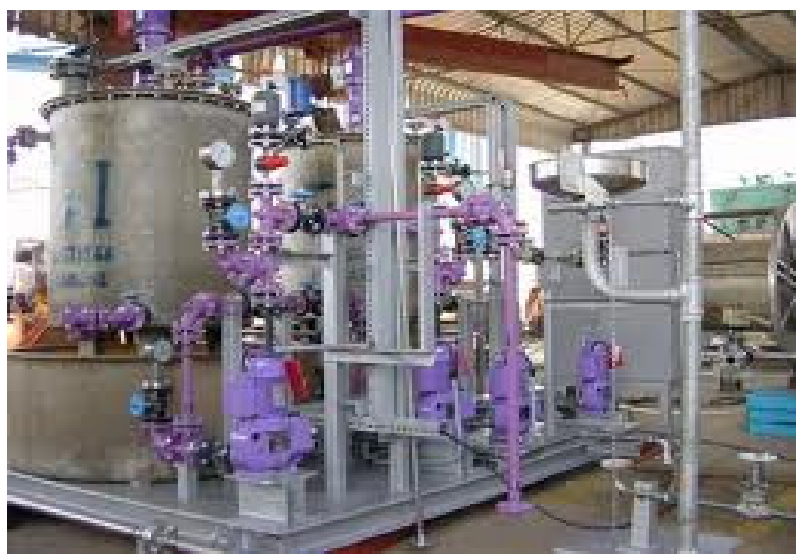

Fig. 19 Typical secondary chemical facility.

8.7 Case Study 7: Refurbishment of Amine Contactor, Regenerator Still Column, Glycol Contactor \& Crude Stabilizer Internals at EPF-50 Revamp

Case brief: For enhanced gas production, improvised and optimized mass transfer rates, the contactor column internals required revamping. Hi-fi (high efficiency) proprietary valve type tray arrangements are used to replace the conventional/bubble cap type trays, along with vane type proprietary gas inlet device (Schoepentoeter) as shown in Figs. 20 and 21 below for the Amine contactor.

Lesson learned from vessel/tower internals replacement: The tower/vessel modifications that require welding of internal tray support rings and nozzle modifications needed proper planning to undergo PWHT (post weld heat treatment) \& repair work under ASME “R” code requirements.

\subsection{Summary of Case Studies}

The above case studies emphasize the importance of concept selection and studies undertaken in the initial, preliminary design phase as well as in FEED (front-end engineering design) stages of projects in the oil and gas sector for their successful and timely execution.

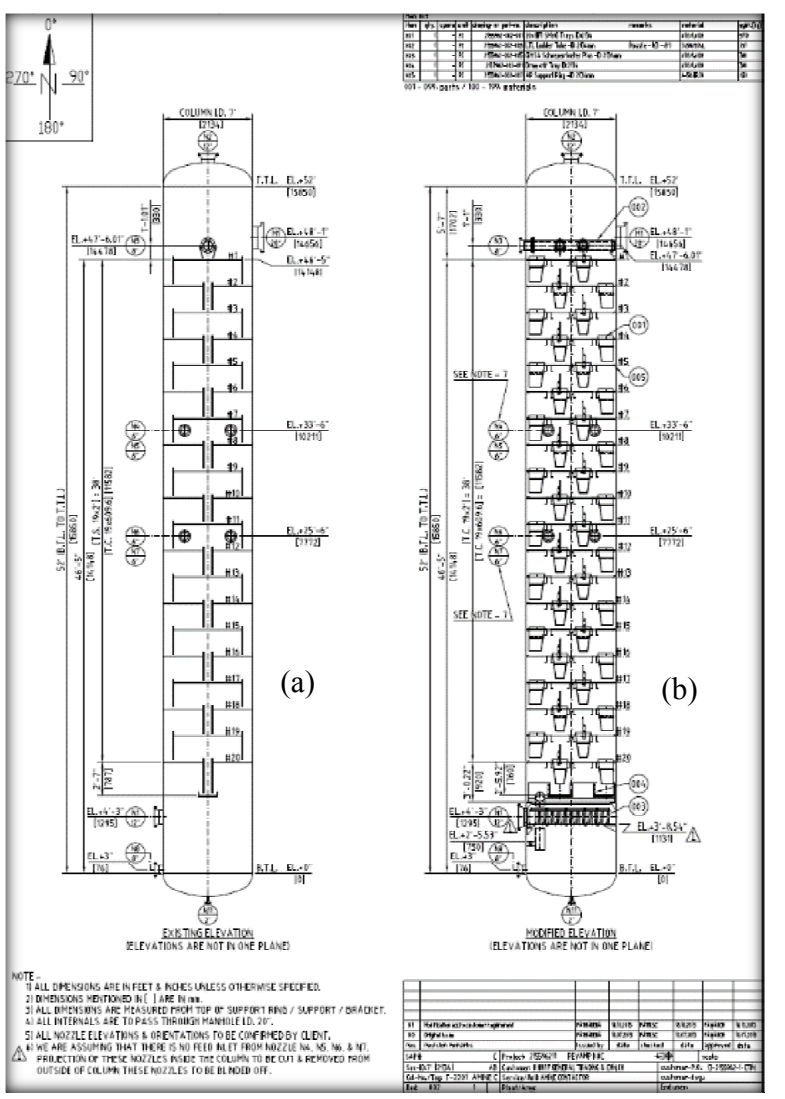

Fig. 20 Amine contactor internals (a) before \& (b) after refurbishment. 


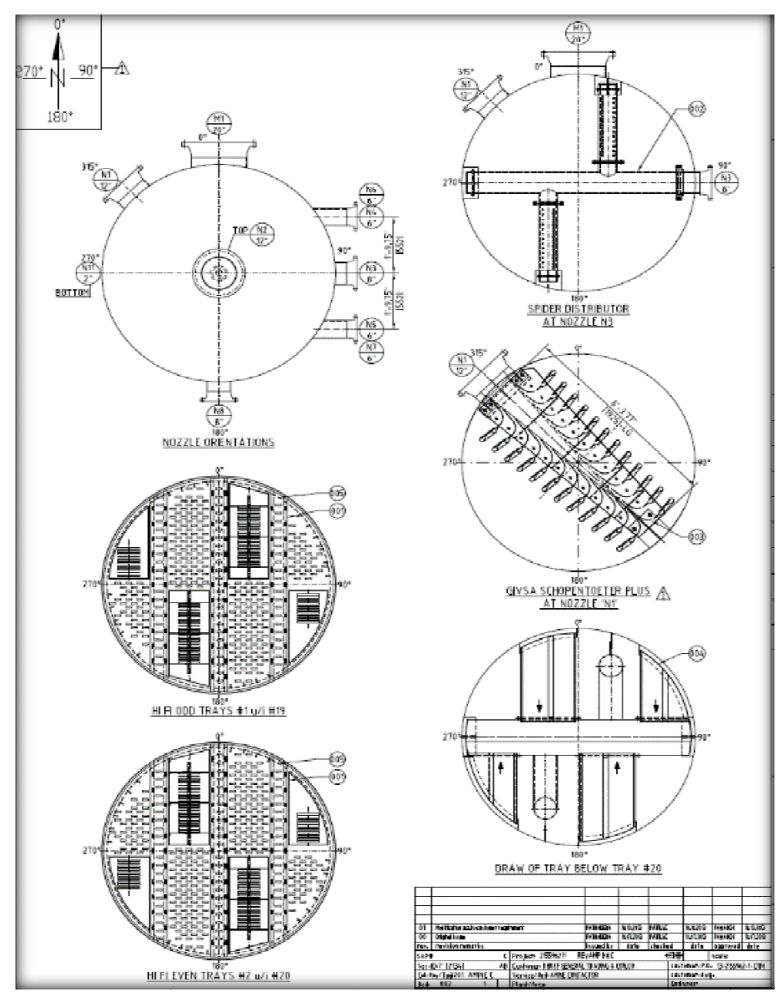

Fig. 21 Few refurbished internal components.

Considerable amount of time $\&$ re-work of facilities and equipment can be saved by proper handling of the basic, initial design engineering.

\section{Conclusions}

Based on the foregoing cases and engineering aspects of projects discussed earlier, it can be concluded that, the technical integrity of facilities and equipment, especially for critical and first time/pioneering projects, largely depends on the engineering efforts made in the conceptual and preliminary design stages.

More importantly, it is for all the involved engineers $\&$ project management personnel to aim for perfection in project engineering activities right from the beginning and strive towards achieving this goal throughout the project cycle.

The novel finding from these case studies and field experience of KOC facilities, that can add value to any project engineering, is the lesson not to rely solely on detail engineering phase for a project to succeed and not to underestimate or trivialize any aspect of conceptual, preliminary and budgetary engineering phases.

\section{Acknowledgments}

The authors would like to acknowledge the support of KOC Management, particularly of Production and Projects Gas Group, and all other Engineers and Staff who have also provided the much necessary support and encouragement in bringing out this paper.

\section{References}

[1] Patrick, J. N., and John, C. 1988. "Gas Turbine Application over Thirty Years in a Middle-East Oil Production Facility." Kuwait Oil Company, ASME paper 88-GT-249.

[2] Technical Integrity Report of Company's Production Facilities (Unpublished).

[3] Crude, Gas \& Condensate Network (KOC, KNPC, MEW)_Flow Schematic Diagram (Unpublished). 